\title{
Nominations Due for 1992 MRS Spring Meeting Graduate Student Awards
}

Nominations for MRS Graduate Student Awards to be presented at the 1992 MRS Spring Meeting, April 27 - May 1 in San Francisco, California are due at MRS Headquarters by January 30, 1992.

Winners will be selected in two steps. First, a group of finalists will be identified based on the award applications. Then finalists, who will be notified by March 6, 1992 , will be required to give a 10 -minute talk based on their symposium papers at a special session during the 1992 MRS Spring Meeting. Winners will be announced at the Spring Meeting Plenary Session on Wednesday evening, April 29, 1992
The registration fee for the 1992 Spring Meeting will be paid for all finalists, entitling them to MRS membership for the remainder of the 1992 calendar year. Award winners will, in addition, receive a $\$ 250$ cash prize and a plaque.

\section{Eligibility}

To qualify for an MRS Graduate Student Award for the 1992 MRS Spring Meeting, applicants must be registered graduate students whose thesis research closely relates to one of the symposium topics for this meeting. Applicants must be authors or co-authors of symposium papers, but need not be the presenters. MRS member- ship is not required, but the students must attend the 1992 MRS Spring Meeting. Students are not eligible if they receive their degrees more than four months before the meeting.

\section{To Apply}

For more information and application forms, contact:

Materials Research Society

1992 MRS Spring Meeting Graduate

Student Awards-B

9800 McKnight Road

Pittsburgh, PA 15237

Phone (412) 367-3003

Fax (412) 367-4373.

\section{MRS University Chapters}

\section{special projects} $\begin{array}{ll}\text { Projogram } & \text { outside } M R S \\ \text { Format: Any }\end{array}$

Objective: To broaden awareness of materials science education to both professional and nonprofessional communities by providing programs for distribution between University Chapters and MRS Sections and/or for use

Format: Any transferable media.

Respository: MRS Headquarters lending library.

To Obtain Funding: Submit a written proposal detailing project, estimated costs, estimated time of completion, and description of project value to further materials science education.

Deadline for Submission: One month before MRS Spring and Fall meetings.

Review Procedure: Three members of the Academic Affairs Committee review proposals, make recommendations in ranked priority, submit to Academic Affairs Committee for discussion at an MRS meeting, and announce awards after meeting.

For further information, call: Aubrey L. Helms Jr., Chair, MRS Academic Affairs Committee; Lam Research Corp., 49026 Milmont Drive, Fremont, CA 94538, (415) 490-7782, FAX (415) 659-8325 or Lam Research Corp., 9250 Trade Place, San Diego, CA 92126, (619) 549-9900, FAX (619) 549-0521 or Anne Wagner, Academic Affairs Committee Liaison, Materials Research Society, 9800 McKnight Road, Pittsburgh, PA 15237, (412) 367-3003, FAX (412) 367-4373.

\section{Now Available on Loan, Free of Charge from MRS Rheomagic}

A 20-minute video produced by the Alfred University Chapter on the deformation and flow of matter. Geared toward high school or undergraduate students, "Rheomagic" gives a nonscientific explanation of rheological phenomena all around us...congealing pancakes or eggs from a liquid batter; combining saliva with chewing gum to make bubbles; water balloons; making a slurry which is then sintered and compressed to form a ceramic.

Two-week terms. VHS format. Call Anne Wagner at (412) 367-3003. 